\title{
The effect of electromagnetic radiation on the reflectance spectra of prints on hemp papers
}

\section{ABSTRACT}

From the moment of production, paper as a printing substrate is exposed to the process of natural ageing regardless of the type of cellulose fibres in its composition. Accordingly, the prints produced by the various printing techniques are also exposed to several factors that impair the quality of the print i.e. its colour over time. Therefore, it is very important to properly select the printing substrate for achieving a high quality of graphic products. For that purpose, three types of papers with hemp fibres were used as printing substrates which were printed with laboratory hand-operated instrument Esiproof using flexographic cyan (C), magenta $(M)$, yellow $(Y)$ and black $(K)$ water-based inks. Prints were artificially aged in SUnTEST XLS+ test chamber according to standard ASTM D 6789-02 for 48 and 96 hours. Based on changes in the reflectance spectra of each printed ink after exposure to electromagnetic radiation it was noticed how composition of printing substrate strongly influence on colour stability of prints due time. An increase of exposure time to electromagnetic radiation leads to a decrease in the value of the reflectance of the printing substrate and cyan, magenta and yellow prints. It was confirmed how electromagnetic radiation have the greatest impact on the reflectance of yellow print, while the black one is the most stabile regardless of the substrate it was printed on.

\author{
Ivana Plazonić (i) \\ Vesna Džimbeg-Malčić \\ Irena Bates (D) \\ Gabriel Žilić \\ University of Zagreb, \\ Faculty of Graphic Arts, Zagreb, Croatia \\ Corresponding author: \\ Ivana Plazonić \\ e-mail: ivana.plazonic@grf.unizg.hr
}

First received: 2.2.2021.

Accepted: 22.3.2021.

\section{KEY WORDS}

Artificial ageing, flexographic inks, hemp, paper, reflectance spectra

\section{Introduction}

Industrially grown hemp (Cannabis sativa L.) is a plant that has been recognized as an important raw material for many industries, including the paper industry (Danielewicz \& Surma-Ślusarska, 2010; Miao et al., 2014).

This plant features strong and long fibres with low lignin content. In total, 35\% of fibres are classified as long bast fibres, and $65 \%$ are short core fibres. Hemp fibre for paper production must have a fibre length of 15-55 mm (Azeez, 2018). An important feature of this raw material is also the time of growth required after which it can supply the paper industry. It is known that the wood is the main raw material for pulp and paper industry and 20-80 years are required for trees growth to provide fibres for paper production. On the other hand, hemp can reach a height of 4-5 meters in only 80-150 days when it is clas- sified as mature for fibre harvesting. Compared to one hectare of forest, one hectare of hemp can produce four times more paper (Małachowska et al., 2015). However, hemp as a fast-growing alternative to trees is annual plants which results in some disadvantages. Due to the macroscopic structure, there are great differences along the plant from top to bottom in terms of morphological structure and chemical composition. The disadvantages of hemp woody-core pulp and hemp bast fibre pulp as papermaking intermediates proved to be low tear resistance and low tensile strength, respectively. The main reasons for the low tensile strength of hemp bast fibre pulp are the low susceptibility of their fibres for internal fibrillation and low hemicellulose content (Danielewicz \& Surma-Ślusarska, 2017). Regardless of the origin of the cellulose fibres used in the paper industry, paper as a product is subjected to a process of natural ageing. 
This irreversible chemical and physical process occurs slowly over time in all papers from the moment of its production. It involves numerous interactions between substances in the paper and with its surroundings (Radkova et al., 2015; Černič Letnar \& Kropar Vančina, 2002), causing structural changes and chemical composition of the material leading to the changes in the functional properties of material (Żołek-Tryznowska \& Annusik, 2019). Therefore, the samples produced by the printing on the paper substrates are also exposed to several factors that impair the print quality i.e. its colour over time. These changes are manly observed as a fading of colours on prints. So, it is particularly important to select the printing substrate which will provide the required quality of graphic products due time. The stability of paper and prints during the ageing process is largely determined by composition of the paper, printing ink and their interaction during printing process. To evaluate the permanence of paper or print different methods of accelerated/artificial ageing have been used by researchers all over the world. These methods include aggravated conditions of heat, humidity, oxygen, sunlight, vibration, etc. to speed up the normal ageing processes of items. UV radiation is the primary cause of degradation in inks, in combination with temperature and moisture acting as secondary stressors that can accelerate the rate of degradation (Lind et. al., 2004). Namely, light as a visible part of spectrum is divided into ultraviolet light (UV), visible light, and infrared energy (IR) that have the shortest to the longest wavelength, respectively. UV light has the highest energy among the electromagnetic spectrum because the short wavelength exhibits higher energy due to the higher frequency of the waves at the same speed of light in space. UV light breaks the chemical bonds of molecules in objects, including colour of printed materials. The molecules of the colour absorb UV light and activate a chemical reaction of electrons leading to photochemical degradation, while the degradation visually affects colour degradation or colour fading (Narakornpijit, 2018). However, artificial ageing of paper can just partially simulate the natural ageing mechanisms such as hydrolysis, oxidation, and photodeterioration (Zervos, 2010).

In our previous research (Plazonic et al., 2020b; Plazonic et al., 2018) results indicate that hemp fibres can produce high-quality office papers that are more stable under light and temperature influences than those made with post-consumer fibres. However, to increase the durability of manufactured papers, hemp fibres must be bleached. However, the composition of paper as a printing surface is only one of the factors that ensure the quality of the printed graphic product. Another factor is the chosen printing technique, as well as the ink that will interact with the printing substrate, but the negative impact of external climate conditions to which printed products are often exposed to is extremely important. Generally, black and cyan will fade only slightly, while at the same time yellow and magenta will noticeably fade. Yellow absorbs visible blue light ( $450 \mathrm{~nm}-495 \mathrm{~nm}$ ) which has the highest energy of visible electromagnetic radiation, so yellow will show more significant discoloration than other process colours (Narakornpijit, 2018). Ink is structurally a dispersion system consisting of pigment, binder and solvent, and it is proven that with the lower ink pigmentation concentration is the lower the lightfastness (Aydemir, Yenidoğan \& Özsoy, 2019). It is important to emphasize that the film thickness of the ink on the surface of the print substrate is highly decisive in light resistance. When the thickness of the ink film increases, the light fastness will be higher as the number of pigments affected by the light in a certain region will increase. Therefore, it is important to maintain a continuous ink thickness during printing (Aydemir \&Yenidoğan, 2018). In general, the stability of an ink layer to UV light depends on the exposure of the ink to light, as well as on the thickness, transparency, pigmentation, filler content factors, or white pigment in the ink film (Aydemir et al., 2021). Studies of effect of electromagnetic radiation on the stability of the ink layer on paper substrates are limited, especially in the field of flexographic printing.

The aim of this study was to evaluate the stability of flexographic print on substrates with hemp fibres based on the reflectance spectra measurements after artificial ageing in Suntest XLS+ test chamber which emits visible and near ultraviolet electromagnetic radiation in range from $290 \mathrm{~nm}$ to $800 \mathrm{~nm}$.

\section{Materials and methods}

\section{Paper as a printing substrate}

In this study three types of office papers were used. Their basic characteristics are summarized in Table 1 .

\section{Table 1}

Characteristics of hemp fibre-based paper used as printing substrates

\begin{tabular}{c|c|c}
\hline Type 1 & Type 2 & Type 3 \\
\hline $\begin{array}{c}\text { 100\% hemp } \\
\text { plant fibre }\end{array}$ & $\begin{array}{c}\text { 90 } \mathrm{g} / \mathrm{m}^{2} \\
\text { 100\% hemp } \\
\text { plant fibre }\end{array}$ & $\begin{array}{c}25 \% \text { hemp and } 75 \% \\
\text { post-consumer } \\
\text { waste fibres }\end{array}$ \\
\hline $100 \%$ sustainable & $100 \%$ sustainable & $100 \%$ sustainable \\
\hline unbleached & $\begin{array}{c}\text { non-chlorine } \\
\text { bleached }\end{array}$ & $\begin{array}{c}\text { acid free, } \\
\text { chlorine free }\end{array}$ \\
\hline uncoated & uncoated & uncoated \\
\hline handmade & handmade & industrial \\
\hline
\end{tabular}

In previous research (Plazonic et al., 2016) it was found that paper Type 3 has the highest share of inorganic com- 
ponents $\left(6.35 \%\right.$ of $\mathrm{CaCO}_{3}$ and $0.75 \%$ of china clay) and consequently the highest share of ash $\left(\mathrm{ash}_{525^{\circ} \mathrm{C}}=7.01 \%\right)$. Papers made only from virgin hemp fibres, papers Type 1 and Type 2, have a low share of ash $\left(\operatorname{ash}_{525^{\circ} \mathrm{C}}<2.4 \%\right)$.

\section{Full tone prints}

All papers were cut in dimensions $190 \mathrm{~mm} \times 40 \mathrm{~mm}$ and subjected to manual printing using a print tester Esiproof (RK print). The cyan (C), magenta (M), yellow (Y) and black (K) prints were made in full tone by Iroflex 917 inks manufactured by Sun Chemical (Table 2). For producing quality flexographic prints, ceramic anilox roller having $40 \mathrm{lin} / \mathrm{cm}^{\circ}\left(60^{\circ}\right.$ spread angle) with a total cell volume of $39.10 \mathrm{~cm}^{3} / \mathrm{m}^{2}$ was used. The purpose of the anilox roller and the doctor blade situated at an angle of $30^{\circ}$ with the tangent point of the anilox roll is to transfer an accurate amount of ink to the surface of the printing plate. The printing process was carried out at a temperature of $23^{\circ} \mathrm{C}$ and a relative humidity of $50 \%$.

To perceive the value of the ink film thickness on hemp papers, the optical ink density $\left(D_{i}\right)$ was determined on all prints by a densitometer eXact, X-Rite (D50/2 $)$. The optical ink density was calculated according to equation 1.

$D_{i}=\log \frac{I_{0}}{l}$

where: I - the light intensity of the light remitted by the ink film in relation to the $I_{0}$ intensity of light,

$I_{0}$ - intensity of the light remitted by unprinted laboratory paper.
The effect of electromagnetic radiation on the optical ink density of cyan, magenta, yellow and black print made on hemp papers was also shown through change of the optical ink density $\left(\Delta D_{j}\right)$ calculated by equation 2 .

$\Delta D_{i}=D_{i \text { before ageing }}-D_{i \text { after ageing }}$

where: $\Delta D_{i}$ - change of the optical ink density;

$D_{\text {ibefore ageing }}$ - the optical ink density of cyan, magenta, yellow and black print measured before ageing;

$D_{\text {iafter ageing }}$ - the optical ink density of cyan, magenta, yellow and black print measured after 96 hours of ageing.

\section{Artificial ageing of papers and prints}

Papers and prints were cut into strips $60 \mathrm{~mm} \times 90 \mathrm{~mm}$ and placed side by side in Suntest XLS+ test chamber, supplied with a daylight filter, which emit visible and near ultraviolet electromagnetic radiation in wavelength range from $290 \mathrm{~nm}$ to $800 \mathrm{~nm}$. The procedure of artificial ageing was carried out according to ASTM D 6789-02, during which the level of light intensity was $(765 \pm 50) \mathrm{W} / \mathrm{m}^{2}$, the temperature was kept at $22.6^{\circ} \mathrm{C}$ and relative humidity was $50 \%$. Exposure to the UV radiation was performed in 2 cycles for 48 hours and in Table 3 is given information about ageing course. UV dose is the product of UV intensity (expressed as energy per unit surface area) and residence time (Feller, 1994) so it can be calculated by equation 3 :

UV dose $=1 \times t$

Table 2

Prints

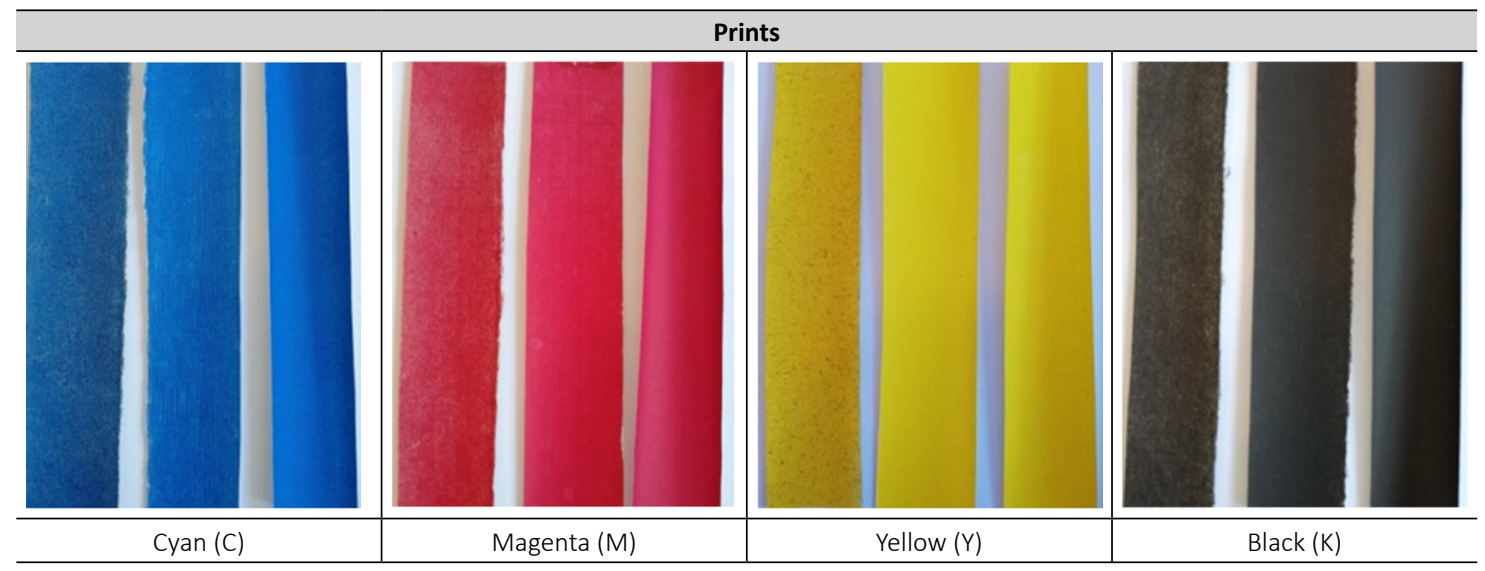

Table 3

Course of ageing in the Suntest XLS+ test chamber

\begin{tabular}{|c|c|c|c|}
\hline Ageing cycle no. & Time of ageing $(h)$ & $\begin{array}{c}\text { Dose of energy } \\
\text { supplied }\left(\mathrm{kJ} / \mathrm{m}^{2}\right)\end{array}$ & $\begin{array}{c}\text { Natural ageing comparable } \\
\text { time (days) }\end{array}$ \\
\hline 1 & 48 & 132192 & 44.5 \\
\hline 2 & 96 & 264384 & 89.0 \\
\hline
\end{tabular}


where: I- intensity or energy per unit surface area expressed in $\mathrm{J} /\left(\mathrm{cm}^{2} \mathrm{sec}\right)$;

$t$ - exposure time in sec.

According to the ageing conditions used in this study, every hour spent in the ageing test chamber corresponds a dose of energy absorbed of $2754 \mathrm{~kJ} / \mathrm{m}^{2}$, which is compatible with approximately 22 hours of natural ageing. This is in correlation with the statement that one hour of treatment under a xenon lamp corresponding to one day in nature (Debeljak \& Gregor-Svetec, 2010; Izdebska, Żołek-Tryznowska \& Książek, 2013).

\section{Spectrophotometric analysis}

Papers and prints reflectance measurements were processed using a spectrophotometer $\mathrm{X}$-rite SpectroEye, in the wavelength interval from $400 \mathrm{~nm}$ to $700 \mathrm{~nm}$ for every $10 \mathrm{~nm}$. The reflectance measured over white background under illuminant D50 (daylight $5000^{\circ} \mathrm{K}$ ), $2^{\circ}$ standard observers, directional geometry, was the basis for the evaluation of optical properties of experimental samples. During the spectrophotometric measurements, the relative humidity of the atmosphere was approximately $60 \%$ and the temperature was around $21^{\circ} \mathrm{C}$. These measurements were supported by ColorShop 2.0 software and analysed by Technical Graphic Origin 6.0 Professional. The reflectance spectra of all samples before and after artificial ageing for both period of time (48 and 96 hours) was measured, and the results of reflectance measurements are presented as $\Delta R$ according to the following equation (4):

$\Delta R=R_{\text {before ageing }}-R_{\text {after ageing }}$

\section{Results and Discussion}

Since paper is a complex structure consisting mainly of a network of fibres, filler pigment particles and air, light is not only reflected on paper surface. Within the surface layer, that is, in the paper structure, light also interacts with fibres and pigments. Therefore, in Figure 1 are presented the reflectance spectra for each paper type which are used as a printing substrate.

The spectral reflectance curves shown in Figure 1a-c confirm that papers used in this study as the printing substrate differ greatly in composition. The reflectance curves of paper containing only virgin hemp fibres in their composition are similar (Figure 1a-b), while the reflectance intensity for paper in which the fibres undergo a bleaching process (Type 2) over the entire whole visible part of the spectrum is higher than for paper whose fibres are not bleached (Type 1). This shape of curve is characteristic of pure cellulose/ ashless papers such as filter paper (Plazonic, Barbaric-Mikocevic \& Dzimbeg-Malcic, 2009). Industrial made paper with $25 \%$ of virgin hemp fibres in its composition and $75 \%$ of recycled fibres (Type 3 ) have a totally different spectral reflectance curve as was expected.
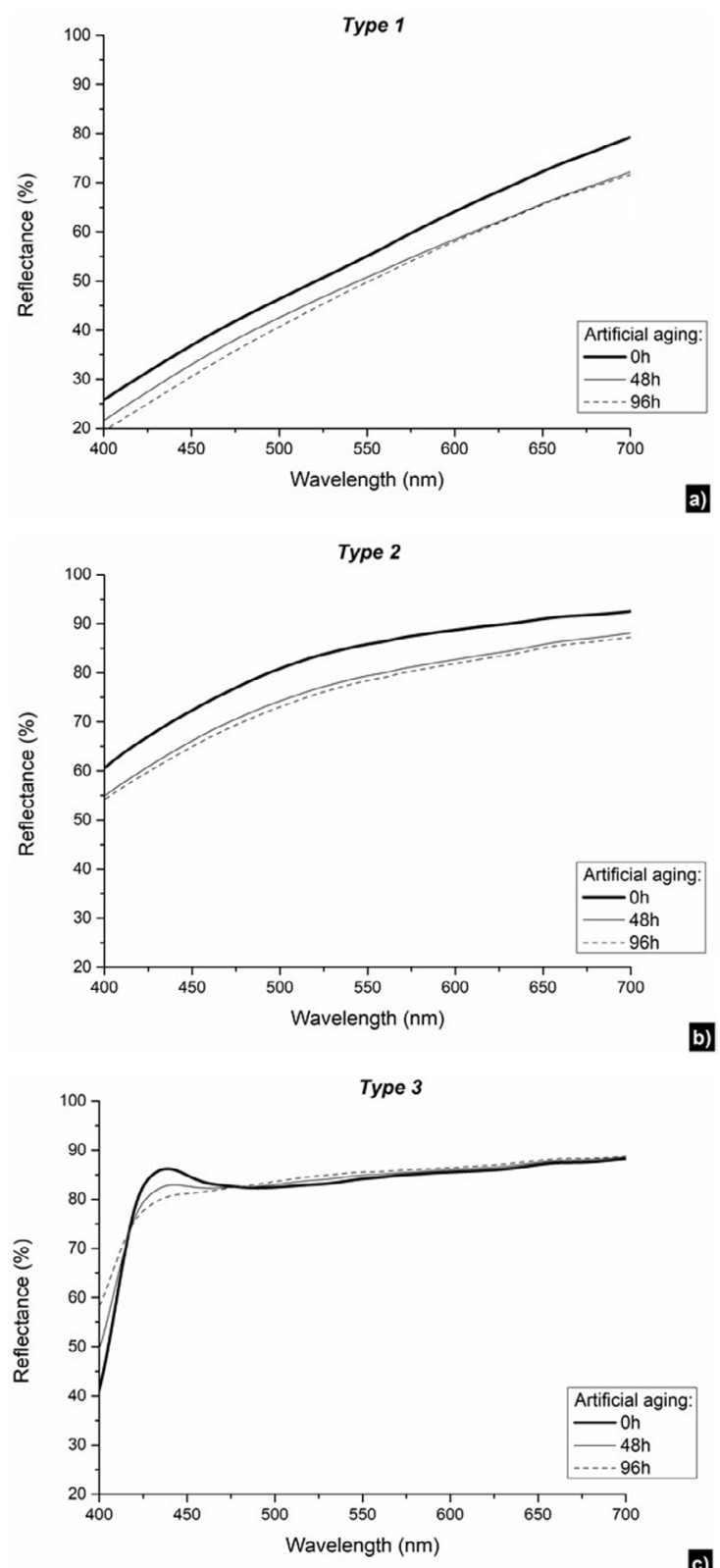

» Figure 1: Spectral reflectance curves of the analysed printing substrates: a) paper Type 1; b) paper Type 2; c) paper Type 3

It can be seen from Figure 1c that in addition to bleached paper, this paper also contains a large amount of filler as it intensely reflects light between $420 \mathrm{~nm}$ and 480 $\mathrm{nm}$. This shape of the reflectance curve is characteristic for office papers with large amount of fillers as calcium carbonate and clay (Plazonic, Barbaric-Mikocevic \& Dzimbeg-Malcic, 2015). By ageing the reflectance of all analysed printing substrates decreases noticeable after $48 \mathrm{~h}$, while further exposure to electromagnetic radiation resulted in a slight decrease in the reflectance. It is also evident that artificial ageing by exposure to electromag- 


\section{Table 4}

The optical ink density $\left(D_{i}\right)$ of prints and changes in optical ink density $\left(\Delta D_{j}\right)$ effected by electromagnetic radiation

\begin{tabular}{|c|c|c|c|c|c|c|}
\hline \multirow{2}{*}{ Print } & \multicolumn{3}{|c|}{$D_{i}$} & \multicolumn{3}{|c|}{$\Delta D_{i}$} \\
\hline & Type 1 & Type 2 & Type 3 & Type 1 & Type 2 & Type 3 \\
\hline Cyan & $0.99 \pm 0.03$ & $1.16 \pm 0.02$ & $1.16 \pm 0.01$ & 0.04 & 0.02 & 0.01 \\
\hline Magenta & $1.03 \pm 0.05$ & $1.29 \pm 0.01$ & $1.22 \pm 0.01$ & 0.08 & 0.07 & 0.01 \\
\hline Yellow & $0.82 \pm 0.03$ & $1.13 \pm 0.02$ & $1.21 \pm 0.01$ & 0.24 & 0.37 & 0.25 \\
\hline Black & $1.01 \pm 0.05$ & $1.32 \pm 0.01$ & $1.25 \pm 0.01$ & 0.01 & 0.02 & 0.00 \\
\hline
\end{tabular}

netic radiation causes approximately the same decrease in the reflectance of both papers with $100 \%$ hemp fibre content over the entire whole visible part of the spectrum. For paper Type 3, it was noticed that electromagnetic radiation did not affect the intensity of the spectral reflectance in the visible part of the spectrum in the wavelength range from $480 \mathrm{~nm}$ to $700 \mathrm{~nm}$, just in the blue part of spectrum (420 nm $-460 \mathrm{~nm}$ ). In our previous research where effect of photo-oxidation on the properties of this hemp office papers were analysed, it was founded that hemp fibres can produce high-quality office papers that are more stable against light and temperature influences than those made with post-consumer fibres. Namely, results of strength properties (tensile index, elongation at break, tear index), surface properties (Bendtsen roughness, Bekk smoothness), pH of paper extracts, and optical properties have pointed out that for increasing the durability of manufactured papers, hemp fibres must be bleached. A main purpose of bleaching the pulp is to remove the residual lignin and chromophores inside the pulp, which efficiently absorb UV radiation and cause paper degradation (Plazonić et al., 2020b).

The Type 1 and Type 2 samples are handmade papers, and their smoothness is lower than the smoothness of industrially made paper. However, Type 1 made from unbleached hemp fibres was detected as paper with the roughest surface (Plazonić et al., 2020a). Although the anilox roller provides the transfer of an equal amount of ink to the printing plate, and from the printing plate to the paper, the rougher surface of the paper Type 1 resulted in lower optical ink density for all inks (Table 4). This is because the transferred ink on the rough surface of the paper penetrates the paper after filling the irregular surface (Ha, Park \& Kim, 2019). As it is clearly seen from Table 4, the highest effect of electromagnetic radiation after 96 hours was observed on the optical ink density of yellow ink regardless of the composition of paper, while the black ink was the most stable. From the $\Delta D_{i}$ results it is also visible that the prints on industrially made paper (Type 3) are the most stable regardless of the printed ink.

From the differences of reflectance curves between the non-aged and artificial aged specimens shown in Figure 2, it can be seen that the unprinted substrate Type 1 undergoes the greatest reflectance changes due to exposure to electromagnetic radiation across the whole visible part of the spectrum ( $\Delta R=3.9 \%-7.9 \%)$. It is also evident that the reflectance values of the printing substrate (on graph marked with grey colour) decrease with increasing the exposure time (from $48 \mathrm{~h}$ to $96 \mathrm{~h}$ ).

Type 1

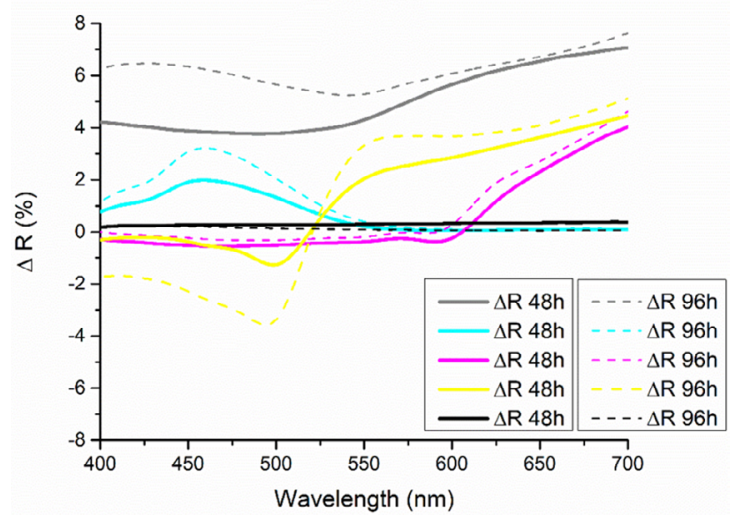

» Figure 2: Differences of reflectance spectra measurements before and after artificial ageing of paper Type 1 and of prints on that paper with cyan, magenta, yellow and black inks

On the other hand, prints (on graph each print is marked with similar colour: cyan print with blue colour; magenta print with pink colour; yellow print with yellow; black print with black colour) are far less susceptible to changes in reflectance values than the paper substrate Type 1 on which they are printed. The artificial ageing in general regardless to the exposure time to electromagnetic radiation has no effect on the reflectance of black prints. This is in correlation with the research results provided by Bates, Džimbeg-Malčić \& Itrić where spectral changes reflection colour in black offset prints on analysed coated and uncoated papers were insignificant and most likely were influenced by printing ink (Bates, Džimbeg-Malčić \& Itrić, 2012) and our previous research (Plazonić et al, 2020b). Other prints (cyan, magenta and yellow) show a change in the reflectance with ageing treatment and the longer the treatment, the greater is the decrease in reflectance values in an area in which a particular colour reflects (cyan in the blue part of the spectrum, magenta in the red part) except for yellow prints which show changes in reflectance throughout the whole visible part of the spectrum. It is evident that yellow prints experience the greatest changes in reflectance due to artificial ageing. 


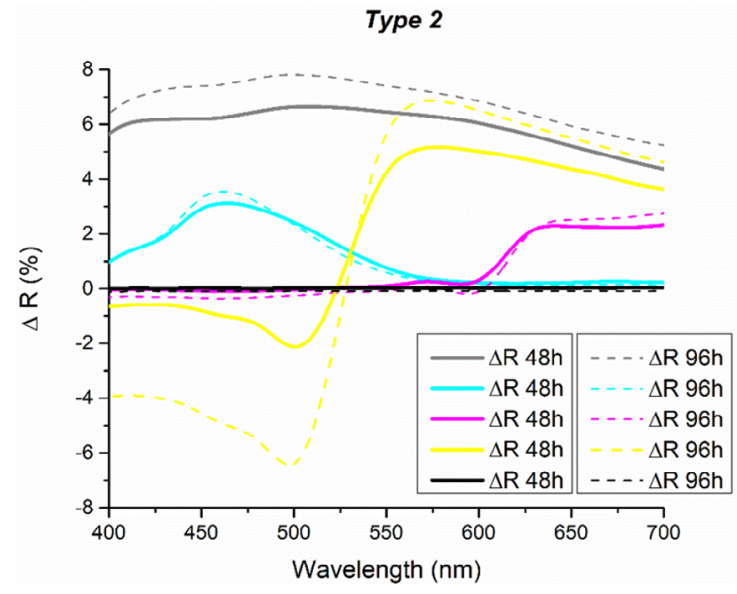

» Figure 3: Differences of reflectance spectra measurements before and after artificial ageing of paper Type 2 and of prints on that paper with cyan, magenta, yellow and black inks

Since the composition of the paper Type 2 is identical to the paper Type 1 (only difference is bleaching process before paper formation), Figure 3 shows quite similar reflectance curve shapes with differences in the intensity. It is evident that bleached paper substrate Type 2 undergoes the largest reflectance changes in the whole visible part of the spectrum due to exposure to electromagnetic radiation ( $\Delta R=4.2 \%-7.9 \%)$. It has been observed that bleached paper Type 2 is also significantly affected by time of ageing where the reflectance of paper is significantly reduces as exposure time increases. All prints are more stable to visible and near ultraviolet electromagnetic radiation than the paper substrate itself. Black prints are unchanged in spectral reflections, while other prints experience a change in reflectance due to artificial ageing, especially yellow prints up to $6.5 \%$ after $96 \mathrm{~h}$ of ageing.

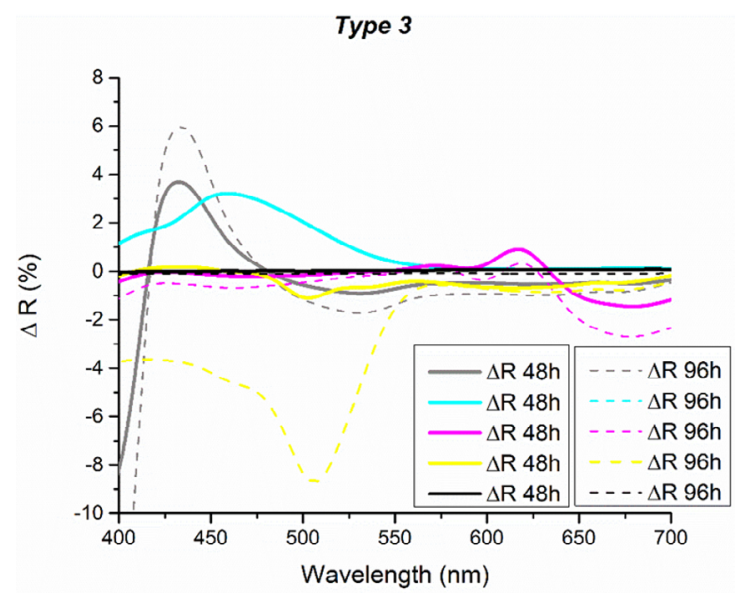

» Figure 4: Differences of reflectance spectra measurements before and after artificial ageing of paper Type 3 and of prints on that paper with cyan, magenta, yellow and black inks
It can be seen from Figure 4 that the industrial made paper Type 3, which contains a much larger amount of recycled than primary hemp fibre and a high amount of fillers, shows greater stability to electromagnetic radiation than other two handmade papers with a $100 \%$ hemp fibre content. The only reflectance differences for the paper Type 3 due to artificial ageing were observed in the blue part of the spectrum (maximum value of $\Delta R$ is $6 \%$ at $430 \mathrm{~nm}$ ) which is a consequence of high share of fillers in it. Prints on this substrate are also much more stable than prints on handmade papers for both periods of exposure to electromagnetic radiation. The significant influence of electromagnetic radiation after $96 \mathrm{~h}$ was noticed only on the reflectance of yellow prints in the blue and green part of the spectrum.

These results of reflectance spectra measurements after artificial ageing of 96 hours are correlated with the optical ink density of prints on hemp apers presented in Table 4.

\section{Conclusions}

The aim of this study was to evaluate the usability of hemp fibre based papers for long-term prints. The stability of flexographic prints on such substrates is based on the differences in reflectance spectra for each ageing period. This study has confirmed that the printing substrate significantly influence on the stability of the prints when exposed to electromagnetic radiation. Namely, if the substrate itself is less susceptible to electromagnetic radiation it will provide more stable prints. It is very important to choose the appropriate printing substrate to increase stability of prints, because every paper substrate goes through a degradation process during the time. Interaction between printing substrate and ink are crucial for print stability. Equal transfer of the ink amount to the printing plate and from the printing plate to the paper is enabled by the anilox roller, while the characteristics of the paper surface, such as roughness, reduce the ink thickness, ie the lower optical density ink on the paper. Based on the reflectance spectra of prints on hemp fibre based papers, we concluded that the black print show equal stability to artificial ageing regardless to chemical composition of hemp fibre based papers $(\Delta R<0.5 \%)$. The lowest stability on electromagnetic radiation was achieved by yellow prints on all observed substrates ( $\triangle R$ up to $8.5 \%$ ). It can also be concluded that with increasing exposure time of electromagnetic radiation reflectance values of printing substrates and cyan, magenta and yellow prints generally decreases.

\section{Acknowledgments}

The authors are grateful for the funding provided by the University of Zagreb. 


\section{References}

Aydemir, C. \& Yenidoğan, S. (2018) Light fastness of printing inks: a review. Journal of Graphic Engineering and Design. 9 (1), 37-43. Available from: doi: 10.24867/ JGED-2018-1-037

Aydemir, C., Kašiković N., Horvath C. \& Durdevic S. (2021) Effect of paper surface properties on ink color change, print gloss and light fastness resistance. Cellulose chemistry and technology. 55 (1-2), 133-139. Available from: doi: 10.35812/CelluloseChemTechnol.2021.55.14

Aydemir, C., Yenidoğan, S. \& Özsoy S. A. (2019) Effects of ink consumption on print quality on coated cellulose-based paper surfaces. Cellulose chemistry and technology. 54 (1-2), 89-94. Available from: doi: 10.35812/CelluloseChemTechnol.2020.54.10

Azeez, A. M. (2018) Pulping of Non-woody Biomass. In: Kazi, S. N. (ed.) Pulp and Paper Processing. London, United Kingdom, IntechOpen, pp. 55-87. Available from: doi: 10.5772/intechopen.79749

Bates, I., Džimbeg-Malčić, V. \& Itrić, K. (2012) Optical deterioration of samples printed with basic Pantone inks. Acta graphica, Journal for Printing Science and Graphic Communications. 23 (3-4), 79-90.

Černič Letnar, M. \& Kropar Vančina, V. (2002) The Effect of Accelerated Ageing on Graphic Paperboards Degradation. Restaurator. 23, 118-132. Available from: doi: 10.1515/REST.2002.118

Danielewicz, D. \& Surma-Ślusarska, B. (2010) Processing of Industrial Hemp into Papermaking Pulps Intended for Bleaching. Fibres \& Textiles in Eastern Europe. 18 (6 (83)), 110-115.

Danielewicz, D. \& Surma-Ślusarska, B. (2017) Properties and fibre characterisation of bleached hemp, birch and pine pulps: a comparison. Cellulose. 24, 5173-5186. Available from: doi: 10.1007/s10570-017-1476-6

Debeljak, M. \& Gregor-Svetec, D. (2010) Optical and Color Stability of Aged Specialty Papers and Ultraviolet Cured Ink Jet Prints. Journal of Imaging Science and Technology ${ }^{\circledR} .54$ (6), 060402-1-060402-9. Available from: doi: 10.2352/J.ImagingSci.Technol.2010.54.6.060402

Feller, R. L. (1994) Accelerated Aging: Photochemical and Thermal Aspects, Research in Conservation 4. Marina del Rey, California, The Getty Conservation Institute, p. 280.

Ha, Y.-B., Park, J.-Y. \& Kim, H.-J. (2019) Influence of the Physical Properties of Digital Printing Paper on the Printing Quality. Journal of Korea Technical Association of the Pulp and Paper Industry. 51 (2), 108-120. Available from: doi: 10.7584/JKTAPPI.2019.04.51.2.108

Izdebska, J., Żołek-Tryznowska, U. \& Książek, T. (2013) Influence of artificial aging on cellulose film. The optical properties of printed and non-printed biodegradable film bases. Agro FOOD Industry Hi Tech. 24 (5), 52-56.

Lind, J., Stack, J. \& Everett, E. T. (2004) Fade Resistance of Lithographic Inks: A New Path Forward-Part 1. GATFWorld. 28-32.

Małachowska, E., Przybysz, P., Dubowik, M., Kucner, M.
\& Buzała, K. (2015) Comparison of Papermaking Potential of Wood and Hemp Cellulose Pulps. Ann. WULS SGGW, Forestry and Wood Technology. 91, 134-137.

Miao, C., Hui, L.-F., Lui, Z. \& Tang, X. (2014) Evaluation of Hemp Root Bast as a New Material for Papermaking. Bioresources. 9 (1), 132-142. Available from: doi: 10.15376/biores.9.1.132-142

Narakornpijit, N. (2018) A Study of the Lightfastness of High-Chroma Water-Based Flexographic Printing Inks. $\mathrm{PhD}$ thesis. Rochester Institute of Technology.

Plazonic, I., Barbaric-Mikocevic, Z. \& Dzimbeg-Malcic, V. (2009) Office papers stability during accelerated ageing. In: Katalinic, B. (ed.) DAAAM International Scientific Book 2009. Vienna, Austria, DAAAM International, pp. 333-340.

Plazonic, I., Barbaric-Mikocevic, Z. \& Dzimbeg-Malcic, V. (2015) Optical stability of office papers treated with cocamidopropyl betaine. Wood research. 60 (2), 263272.

Plazonić, I., Barbarić-Mikočević, Ž., Bates, I. \& Malnar, L. (2016) Chemical stability of prints made on hemp fibre based papers. Acta Graphica. 27 (3), 25-30.

Plazonić, I., Bates, I., Džimbeg-Malčić, V. \& Zember, D. (2020a) Colorimetric changes of waterbased flexographic ink printed on hemp-based papers exposed to artificial ageing. In: Dedijer, S. (ed.) Proceedings - The Tenth International Symposium GRID 2020, GRID 2020, 12-14 November 2020, Novi Sad, Serbia. Novi Sad, University of Novi Sad, Faculty of Technical Sciences, Department of Graphic Engineering and Design, pp. 57-62. Available from: doi: 10.24867/GRID-2020-p3

Plazonic, I., Džimbeg-Malcic, V., Bates, I. \& Barbaric-Mikocevic, Ž. (2020b) Effects of Photo-oxidation on the Properties of Hemp Office Papers, International Journal of Technology. 11 (2), 215-224. Available from: doi: 10.14716/ijtech.v11i2.3196

Plazonić, I., Malnar, L., Džimbeg-Malčić, V., Barbarić-Mikočević, Ž. \& Bates, I. (2018) Changes in the optical properties of hemp office papers due to accelerated ageing. In: Kašiković, N. (ed.) Proceedings of 9th international symposium on graphic engineering and design, GRID 2018, 8-10 November 2018, Novi Sad, Serbia. Novi Sad, University of Novi Sad - Faculty of Technical Sciences, Department of Graphic Engineering and Design, pp. 121-127. Available from: doi: 10.24867/GRID-2018-p14

Radkova, V., Tsekova, P., Ivanova, T. \& Valchev, I. (2015) Effect of dry-heat ageing on label paper quality. Bulgarian Chemical Communications. 47 (Specialissue A), 51-59.

Zervos, S. (2010) Natural and Accelerated Ageing of Cellulose and Paper: A Literature Review. In: Lejeune, A., Deprez, T. (eds.) Cellulose: Structure and Properties, Derivatives and Industrial Uses. Hauppauge, New York, Nova Science Publishers Inc., pp. 155- 203.

Żołek-Tryznowska, Z. \& Annusik, T. (2019) Effect of various conditions of artificial ageing on selected properties of overprinted plastic films. Inovacijos leidybos, poligrafijos ir multimedijos technologijose 2019. 164-173. 


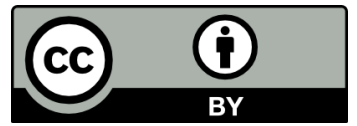

(C) 2021 Authors. Published by the University of Novi Sad, Faculty of Technical Sciences, Department of Graphic Engineering and Design. This article is an open access article distributed under the terms and conditions of the Creative Commons Attribution license 3.0 Serbia (http://creativecommons.org/licenses/by/3.0/rs/). 